\title{
Discurso mediático y encuadres noticiosos sobre la corrupción política en España
}

\author{
Media Discourse and News Frames on Political \\ Corruption in Spain
}

\author{
Salomé Sola-Morales (D) http://orcid.org/0000-0001-7085-4595 \\ Universidad de Sevilla,España,ssolamorales@gmail.com
}

Belén Zurbano-Berenguer (1) https://orcid.org/0000-0002-2743-236X

Universidad de Sevilla, España,bzurbano@us.es

Recepción:

08/05/2018

Aprobación: 02/08/2018

\begin{abstract}
Corruption cases are increasingly recurring in the Hispanic American press. The present article studies, from the standpoint of the interpretative responsibility of journalism, the editorial framework of one of the leading newspapers in Spain. From a qualitative methodology such as Discourse Analysis, this paper responds to the objective of "analyzing the media treatment of political corruption in Spain, through the analysis of the headlines of El País and El Mundo (newspapers with the highest circulation and the largest number of readers in the country)." Among the results, it is worth highlighting a personalization of the treatment of processes and events of corruption, omission responsibilities by the power structures, as well as some editorial bias as regards the nominalization of the different political parties involved in the current topics covered. The main conclusion of this research is the urgent need to encourage a type of press that favors an interpretative contribution, which allows citizenship to understand and comprehend corruption.
\end{abstract}

Key words: discourse, corruption, politics, treatment, mass media.

Resumen: Los casos de corrupción son cada vez más recurrentes en la prensa hispanoamericana. El presente artículo estudia, desde el prisma de la responsabilidad interpretativa del periodismo, el encuadre noticioso y editorial de uno de los diarios referente en España. A partir del Análisis del Discurso (AD), esta investigación ha respondido al objetivo de analizar el discurso mediático sobre la corrupción política en España, por medio de la exploración de los titulares de El País y El Mundo, los dos diarios con mayor tirada y número de lectores en España. Entre los resultados cabe destacar una personalización del tratamiento de los procesos y eventos de corrupción, una des-responsabilización de las estructuras de poder, así como cierto sesgo editorial respecto a la nominalización de los diferentes partidos políticos implicados en los temas de actualidad cubiertos. La conclusión fundamental del estudio es la necesidad urgente de incentivar un tipo de prensa que favorezca un aporte interpretativo de calidad en la ciudadanía ante los casos de corrupción.

Palabras clave: discurso, corrupción, política, tratamiento, medios de comunicación de masas. 


\section{Introducción}

En las últimas décadas, la corrupción política ha invadido las agendas mediáticas de países europeos y latinoamericanos demostrando ser un problema de primer orden para las sociedades democráticas. Es más, en 2016 España batió su récord como nación corrupta obteniendo 58 puntos en el ranking de los países percibidos como corruptos, según datos de Transparencia Internacional (2016). La llamada "trama Gürtel”, el caso Palma Arena, Caja España, Bankia, Tarjetas Black, Filesa, GAL, los cursos de formación de Andalucía, Caso Pujol constituyen un listado de causas y macrocausas judicializadas, que en el contexto peninsular es ingente y cuesta asimilarlas como hechos aislados. Así, se genera un estado de agitación social en el que este problema ha pasado a ser el segundo para la sociedad española, a pesar de verse aún inmersa en los coletazos de la crisis económica. Es más, el 47,5\% de los españoles piensa que el segundo mayor problema de España es la corrupción después del paro, que es el primero, según el Barómetro de febrero de 2016, del Centro de Investigaciones Sociológicas (CIS, 2016) (véase Figura $1^{1}$ ).

Además, en este estudio sociológico (CIS, 2016) se alertaba del aumento de la preocupación ciudadana ante esta escalada en la aparición y cobertura mediática de los procesos de corrupción.

La preocupación por la corrupción y el fraude crece ocho puntos con respecto a la encuesta de enero (del 39,2\% al 47,5\%), mientras que la del paro se mantiene estable. Incluso el $15,4 \%$ considera que la corrupción le afecta personalmente, más de cuatro puntos más que en la encuesta anterior. La ausencia de Gobierno solo preocupa al 1,4\% de los españoles, un porcentaje similar a la inquietud que provoca la independencia de Cataluña (El País, 2016).

No obstante, a pesar de la aparente "moda" de la temática de "corrupción política”, lo cierto es que no es una tendencia nueva ni propia de una sociedad particular (Pérez, 1995). Además, alcanza tanto la vida pública (González, 1999) como la privada (Hodgson y Jiang, 2008). Distintas tradiciones y enfoques epistemológicos han definido la corrupción de diversas formas. Algunos autores han considerado que este fenómeno es algo difuso y que está conceptualmente vacío (Hodgson y Jiang, 2008). Otros investigadores han propuesto tipologías de corrupción en función de su nivel o alcance -político, económico, administrativo- (Boehm y Graf, 2009) o han demarcado divergencias importantes en relación con otros fenómenos como el "clientelismo político" (Caciagli, 1996; Corzo, 2002; Rehren, 2000).

1 Las figuras y las tablas se encuentran en el Anexo, al final del presente artículo (Nota del editor). 
En cuanto a sus causas principales pueden variar en función del contexto del país. Kauffman (2000) afirma que la corrupción está íntimamente conectada con el nivel de desarrollo de un país: los salarios, las políticas en exceso proteccionistas, la falta de libertades, el rol de instituciones como la policía, o un mal funcionamiento del mercado o el poder judicial pueden afectar en la misma.

En la actualidad, las democracias occidentales presentan a la corrupción como la causante de corromper a sujetos e instituciones, como si se tratase de un "cáncer mortal” sin curación posible (Pérez, 1995). Y es que las consecuencias de la corrupción son gravísimas, deterioran la democracia en su esencia (Barreiro y Sánchez-Cuenca, 2000) y hacen perder la credibilidad en la política o provocan climas de inestabilidad difíciles de reponer. El descrédito hacia los partidos que provoca, además, pone en peligro la participación política de los ciudadanos (Pérez y López, 2014; Ordóñez, 2012). Precisamente, en contextos donde ha habido escándalos importantes, los ciudadanos terminan considerando que se trata de una tendencia universal, imposible de combatir, lo cual termina generando apatía y desinterés (Laguna, 2013).

La opinión de que los gobiernos no resuelven este problema cada vez más creciente se ha convertido en lo habitual (Muñoz-López-Carmona, 2012), lógicamente en relación con el aumento de los escándalos. En estos contextos, la ciudadanía se distancia de la política y sus actores principales, lo cual termina produciendo una desinformación que retroalimenta la poca participación, generando, a su vez, mayor corrupción. Como dirían Hodgson y Jian (2008), la pérdida de moralidad democrática hace que se presenten con mayor facilidad formas de totalitarismo.

Además del malestar democrático que genera y del impacto negativo en la sociedad y la ciudadanía, como es obvio, la corrupción también provoca negativas consecuencias en la economía. Los países con mayor desregulación son más inestables, dado que no existen normas que controlen la corrupción, y esto termina provocando graves problemas al mercado (Hodgson y Jiang, 2008). En definitiva, la corrupción es nefasta para la economía, pues impacta sobre el índice de desarrollo humano (Akçai, 2006; Quizilbash, 2001). También, como ha indicado Mauro (2002), afecta el crecimiento económico y genera desigualdades, en los ingresos, por ejemplo; repercute en el abandono escolar o provoca que haya menos inversiones extranjeras, si se citan los efectos más significativos (Larrú, 2009).

En este tenor, el rol de los medios de comunicación masiva es clave. Existen numerosos argumentarios que avalan la importancia capital del 
potencial comunicativo en cuestiones de especial relevancia social. La cobertura informativa de la corrupción es un elemento bueno para medir la calidad de los sistemas democráticos en relación con las dictaduras, como ha indicado Castells (2003). Esto se debe a que "la libre expresión en los medios es el único freno posible a la arbitrariedad de los que gobiernan” (Martínez-Gallego, 2013: 100). Así, los medios deberían funcionar como entes fiscalizadores. Afirmaciones de esta índole beben de las reflexiones clásicas respecto del papel social de los medios de comunicación y ponen en cuestión la vigencia de la Watch-dog theory. ¿Son los medios de comunicación centinelas de la democracia o en realidad hoy en día no son sino mediadores entre instituciones y sociedad?

La teoría clásica que define a la prensa como un perro-guardián de las instituciones se ha convertido hoy en una píldora de intelección, en una cristalización del pensamiento burdamente esquemática, que está sirviendo, entre otras cosas, para legitimar determinadas actuaciones profesionales absolutamente inaceptables. Creo, sin embargo, que el substrato básico de esta tesis sigue siendo válido todavía (MartínezAlbertos, 1994: 3).

Tanto las afirmaciones de Martínez-Albertos (1994) como la de Schiller, para quien los medios de comunicación funcionan como brazos ejecutores del sistema, destacan el viraje mediático desde la periferia vigilante hacia el núcleo mismo del poder, evidenciando cómo el relato mediático se constituye en una mediación y configura la realidad cotidiana.

Autores como Martínez-Albertos (1994) han defendido desde hace unas décadas que los medios son "controladores" del sistema, que ejercen una tiranía del poder (Martínez-Albertos, 1999). No obstante, otros han considerado que no es la información o la comunicación la que vigila al poder, sino que esta es poder en sí mismo y se encuentra en lo más alto de la pirámide del sistema (Labio-Bernal, 2006; Reig, 1998 y 2007).

Tampoco se puede perder de vista que "el conocimiento público del escándalo por corrupción y los juicios que la sociedad formula a su respecto están mediatizados" (Martínez-Gallego, 2013: 104), lo cual quiere decir que los medios construyen relatos sobre la corrupción y sus consecuencias con un determinado valor simbólico. Tal y como han indicado Canel y Sanders (2005 y 2006), el tratamiento de las partes del proceso, como la cobertura de la acusación o la reacción del acusado, son esquemas o micronarraciones estereotipadas que tienden a la repetición.

Además, los medios, más allá de fiscalizar la labor de los políticos, deberían responder a una "moral democrática", a juicio de Pérez-Tapias (1995). ¿Cómo podrían hacerlo? En concreto, mostrando lo que es un sistema sano 
políticamente y evidenciando lo que no es justo o correcto. No obstante, esta lógica moral no es la que predomina muchas veces, debido a la estructura mercantilista de los grandes conglomerados. Es más, termina primando, en muchas ocasiones, la "espectacularización" de los casos de corrupción (Martínez-Gallego, 2013), por la sobrecarga dramática otorgada a las noticias, que es la que configura una interpretación de la mismas (Hierro, 2014; Martínez-Gallego, 2013; Zamora y Marín, 2010 y 2011).

Por todo ello, la corrupción puede ser entendida como un fenómeno de corte interpretativo (Sola-Morales y Rivera, 2017: 649). Valga recordar que los frames son estructuras de significado que facilitan a los individuos la interpretación del mundo y les ayudan a situarse y contextualizarse (Entman, 1993; Goffman, 2006; Reese, 2001; Scheufele, 1999; Tankard, 2001). Entman (1993) define el framing como una selección de aspectos de la realidad con el fin de hacerla más comprensible. Así se describe mejor un problema y se le da una interpretación concreta o una evaluación. Este proceso es bastante evidente en el tratamiento de noticias, ya que jerarquiza y selecciona, omite o silencia, evalúa y categoriza a los personajes que aparecen representados (Sola-Morales, 2014: 133).

A este respecto, los encuadres noticiosos o media frames serían "principios organizativos que se comparten socialmente y constituyen la estructura simbólica y significativa del mundo social" (Sola-Morales, 2014: 132), o lo que es lo mismo: ofrecen un esquema para comprender y juzgar el mundo. Así, "el efecto de los encuadres noticiosos sobre las personas no surge de dar mayor relevancia a ciertos aspectos de un tema, sino de invocar esquemas que influyen en la interpretación de la información recibida" (Aruguete y Zunino, 2010: 42).

Con el objetivo de conocer cuál es el tratamiento mediático de este conflicto estructural que se encuentra en menor o mayor medida en todas las democracias, el presente artículo analiza cómo es la cobertura periodística de la corrupción política de los diarios El País y El Mundo, ambos de pago y en papel, con la mayor tirada y número de lectores en España y, por ende, los líderes de opinión en prensa escrita.

Para conocer el tratamiento mediático de esta temática, se realizará un análisis crítico del discurso de los titulares de las noticias etiquetadas bajo la categoría "corrupción política", de los meses de noviembre y diciembre de 2016. Valga recordar que el análisis crítico del discurso, el CDA, se inauguró con Language and Control (1979), la obra de Roger Fowler et al. y fue continuada por los clásicos estudios de discurso y poder de Fairclough (1989), así como por las obras de Kramarae, Wodak o Van Dijk (Sola-Morales, 2012), 
autores que se han tomado como el horizonte teórico-metodológico de este artículo.

La presente investigación empírica se focaliza en tres aspectos discursivos fundamentales: en primer lugar, en los personajes (su rol y caracterización); en segundo, en las estrategias discursivas -utilizando la terminología de Van Dijk (1980) - que se hallan implícitas en el discurso mediático propiciado por el enfoque de un medio en particular; y, en tercero, en la presencia (implícita o explícita) de los principales partidos políticos en los titulares.

\section{Objetivos e hipótesis}

El objetivo principal es explorar cuál es el discurso periodístico acerca de la corrupción política en España. Para ello se han analizado los titulares de $E l$ Pais y El Mundo, publicados durante dos meses (noviembre y diciembre de 2016). Los objetivos específicos son:

- Determinar cuál es el rol y categorización de los personajes aparecidos en los titulares examinados.

- Explorar cuáles son las estrategias discursivas utilizadas por los periódicos El País y El Mundo en la cobertura de los diferentes casos de corrupción.

- Determinar la presencia de los diferentes grupos políticos en la cobertura periodística que realizan El Pais y El Mundo.

La hipótesis en esta investigación es la siguiente: Los titulares analizados están protagonizados por personajes corruptos (los culpables o villanos). Sin embargo, no tienen presente a los “corruptores" (que bien podrían ser el sistema o los partidos políticos). De este modo se atenúa la responsabilidad de los grupos políticos y de las empresas, ya que se culpabiliza a sujetos individuales.

\section{Fuentes y metodología}

Para profundizar empíricamente el enmarque mediático de la corrupción política en España, se ha llevado a cabo un análisis crítico del discurso, de tenor cualitativo de los titulares publicados en noviembre y diciembre de 2016 en El País y en El Mundo. Se han tomado dos meses para elaborar una ilustración de la propuesta en esta primera etapa de la investigación, con el fin de realizar en el futuro el análisis de un año completo, el desglose pormenorizado de diferentes casos y la posible comparación entre países. 


\section{Muestra}

La muestra está compuesta por 331 titulares: 158 de El País, y 173 de $E l$ Mundo. Cabe señalar que ambos diarios españoles tienen un corte editorial diferente: El País, del grupo Prisa, es de corte progresista y se podría catalogar como de "centro-izquierda"; y El Mundo, del grupo Unidad Editorial, se podría considerar como de "derechas". Es preciso destacar que en esta investigación se ha realizado un análisis pormenorizado de titulares, dado que este tipo de corpus resulta muy adecuado para el estudio de encuadres (Gallardo-Paúls y Enguix, 2014). Los titulares, como es bien conocido, funcionan como activadores del proceso de comprensión textual; es más, remiten a una actividad de focalización atencional (Jorques, 2000: 97). En este sentido, tienen un rol esencial en el proceso de lectura. Si el titular u otros elementos paratextuales (como las gráficas) o visuales (como la imagen) no captan la atención del lector, puede ser que no se lea la noticia completa.

Asimismo, baste indicar que si bien existen numerosos tipos de titulares, en el marco de este estudio periodístico se han hallado, fundamentalmente, titulares informativos, los cuales apuntan a la macroestructura de la noticia, su resumen o significado, y titulares apelativos que pretenden captar la atención del lector mediante estrategias diversas.

\section{Herramientas de análisis}

Respecto a las herramientas metodológicas, se ha desarrollado una ficha de análisis atendiendo al análisis crítico del discurso, como enfoque teóricometodológico en la línea propuesta por uno de sus mayores exponentes: Van Dijk (1980, 1990 y 1991), la cual ha permitido profundizar en torno a tres ejes relacionados con los tres objetivos específicos de la investigación:

1) Para analizar el rol de los personajes - una característica esencial en el CDA- y su caracterización, se delimitaron las siguientes categorías: corrupto o corruptor; víctima, héroe o villano, replicando la estrategia metodológica de un estudio anterior realizado por Sola-Morales y Rivera (2017). En específico, se delimitaron dos tipos de personajes: por una parte, los concretos: aquellos que tienen nombre y apellidos son Bárcenas, PP, Barberá, Rajoy, Bustos o Correa, por ejemplo. Estos personajes concretos aparecen en el titular como sujetos de la acción descrita.

Por la otra, los personajes abstractos como: sistema (definido como el aparato legal y las relaciones institucionales), empresas (sector privado), gobierno (Poder Ejecutivo), los partidos políticos, la sociedad (ciudadanos), la 
Justicia y los jueces, la policía, o la corrupción. Este análisis de personajes abstractos como ya se concluyó en Sola-Morales y Rivera (2017) da cuenta de las informaciones omitidas o los énfasis que pretende hacer el medio en relación con las interacciones y contextos en los que actúan los personajes concretos. Estos dos aspectos: omisiones y énfasis, son cruciales en el CDA.

La estrategia se desarrolló de la siguiente manera: primero, a cada uno de los ítems delimitados se le otorgaron cuatro roles diferenciados (corrupto, corruptor, otro rol y no mencionado). El valor "corrupto" representa al sujeto o institución que perpetra el acto de corrupción en sí mismo. El valor "corruptor" se refiere a quienes corrompen al corruptor. "Otro rol" hace alusión a casos diferentes al propuesto y "no mencionado", lo cual significa que no aparece ninguno de los roles antes señalados. Segundo, se determinó si cada uno de los personajes analizados en ambos diarios -El País y El Mundo- eran representados como víctimas, héroes o villanos. Este análisis se realizó por medio de la configuración del discurso de dichos titulares sobre los personajes, lo cual supuso una perspectiva crítica por parte del codificador, quien se posicionó frente a los personajes del discurso, de acuerdo con las categorías delimitadas previamente.

2) Para examinar las estrategias discursivas subyacentes aparecidas en los titulares escogidos se definieron cuatro estrategias retóricas fundamentales, que han permitido descubrir cómo es la cobertura discursiva de la corrupción. Al hablar de la estrategia textual de encuadre de los titulares hay que tener presente lo siguiente: los titulares cumplen una función semántica-informativa, que resume y adelanta el significado de la noticia; y otra pragmática, que orienta el sentido o la interpretación de la misma. Está claro que en muchas ocasiones los titulares se limitan a reproducir o "copiar" los textos de agencias de prensa, de manera que ya la misma tarea de titular se convierte en una actividad de encuadre, dado que se elige, sobre una batería de noticias, cuáles cubrir. Ahora bien, el análisis planteado, sin embargo, no se centra en este aspecto. Lo que se busca es explorar las estrategias textuales y pragmáticas de los titulares, que bien pueden considerarse implícitas en la medida en que terminan orientando o dirigiendo la interpretación de las noticias de manera indirecta. Es más, si se añaden o se omiten elementos o perfilan matices a este tipo de informaciones el sentido termina variando.

Por ejemplo, la corrupción puede ser catalogada como un delito grave o como una pauta habitual y cotidiana en la que todos (ciudadanos e instituciones) caen sin querer. Justamente para entender cuáles son los encuadres noticiosos o marcos mediáticos que se están transmitiendo a los lectores es 
fundamental cuestionar cuáles son las estrategias retóricas -intencionadas o no- que aparecen en los titulares de los principales diarios.

Las categorías fueron las mismas utilizadas en Sola-Morales y Rivera (2017): a) mitigación o atenuación de la fuerza ilocucionaria; b) idealización o sobrevaloración positiva; c) omisión o ausencia de información relevante; y d) polarización, contraposición entre el "nosotros" y el "otros". Todas ellas son estrategias que el CDA estudia y que influyen directamente en la comprensión del discurso.

3) La presencia/ausencia de los partidos políticos en la cobertura realizada por el diario estudiado se estructuró con base en las siguientes categorías, definidas por el número de partidos políticos con presencia parlamentaria en el Congreso de los Diputados de España para el año 2016: Partido Popular (PP), Partido Socialista Obrero Español (PSOE), Podemos, Ciudadanos, Esquerra Republicana de Catalunya (ERC), Democràcia i Llibertat (DL), Partido Nacionalista Vasco (EAJ-PNV), Partido Demócrata Europeo Catalán (PdeCat), Compromís, Euskal Herria Bildu (EH-Bildu), Unión del Pueblo Navarro (UPN), Coalición Canaria (CC), Foro de Ciudadanos (FAC) y Nueva Canarias (NC).

En este caso, el estudio se ha dirigido a dar cuenta de si existe una referencia a los partidos políticos en los titulares, ya sea explícita, por medio de su nombre o siglas, o implícita, refiriéndose a una trama relacionada o a un personaje del partido acusado de corrupción. Esta fase ha permitido realizar una comparativa entre las dos cabeceras, a fin de determinar si existe una intencionalidad política/ideológica atendiendo a la línea editorial de los medios; a saber, si el El Pais, "pro-PSOE", ha preferido casos de corrupción del PSOE o del PP u otros partidos, y si El Mundo, "pro-PP”, se ha centrado en informar sobre los casos de corrupción del PP o del partido en la oposición.

\section{Resultados}

\section{Roly caracterización de los personajes}

A la luz del análisis de los personajes, se evidenció que El País centra su discurso periodístico sobre la corrupción en los "corruptos" (69\%) y no en los "corruptores" (1\%), y también se centra en los personajes concretos (70\%) por encima de los abstractos (30\%). Además, los personajes abstractos representan una mayor ambigüedad respecto a su rol, ya que muchos de ellos no tienen ninguno asignado dentro del titular (13\%) (véase Figura 2). 
En el caso de El Mundo, la distribución es bastante similar. Los corruptos $(60 \%)$ ocuparon la mayoría del discurso, mientras que los corruptores aparecieron de manera testimonial (6\%). Asimismo, se centra en los personajes concretos $(80 \%)$ por encima de los abstractos (20\%) (véase Figura 3).

En este sentido, ambos medios transmiten la idea de que la corrupción es una acción enmarcada en una personalidad concreta, señalando directamente al culpable o al responsable de la misma con un nombre y un apellido, resaltando un cargo o colocando como sujeto de la acción a un partido político específico. Para analizar a los personajes representados, se utilizaron las mismas variables indicadas. No obstante, para explorar los elementos narrativos enunciados por los redactores de los titulares, se indicaron cuatro valores nuevos (héroe, villano, víctima y no menciona). Esta categorización tuvo por objetivo describir la noticia a partir de la valoración de los personajes, los cuales se identifican con instituciones o sujetos determinantes en los casos de corrupción.

Respecto a la caracterización de los personajes, a continuación se presentan los resultados pormenorizados de los roles (no mencionado, víctima, héroe y villano) de los personajes concretos analizados (Bárcenas, PP, Barberá, Correa, Bustos, Pujol, Granados, Chávez, Extranjero y otro) y de los abstractos (sistema, empresas, sociedad, gobierno, justicia, policía, partidos). Los datos mostraron cómo los personajes concretos seleccionados juegan un rol de "villanos" en su mayoría (n=125, en El Pais, y n= 66 en El Mundo) (véanse tablas 1 y 2).

Por el contrario, los personajes abstractos -más numerosos en El País $(\mathrm{n}=57)$, que en ElMundo $(\mathrm{n}=23)$ - son categorizados como "héroes" ( $\mathrm{n}=27$, en El Pais, y n= 8 en El Mundo) en su mayoría (véanse tablas 3 y 4 ).

\section{Estrategias discursivas}

En cuanto al discurso mediático y a las intenciones de El País y El Mundo, en la Figura 5 se muestra cómo los titulares analizados crearon una perspectiva muy particular sobre los casos de corrupción, utilizando estrategias retóricas diversas (véase Figura 5).

Se encontraron diferencias significativas entre ambas cabeceras. Los titulares de El Pais presentan una posición discursiva muy marcada por la polarización. Del total de 158 titulares, esta estrategia apareció en 92 casos; después le siguió la idealización con un total de 30 casos; y al final, la mitigación y la omisión (16 y 20 casos, respectivamente). La polarización posicionó a la corrupción en la agenda mediática como una lucha, oposición 
o confrontación entre un "nosotros" (los ciudadanos buenos y el gobierno bueno), frente a un "ellos" (los corruptos, los malos).

El discurso estuvo muy marcado por la dualidad entre los jueces o los policías (sin nombre ni apellidos) y los corruptos (culpables con nombre y apellidos). En El Mundo, la idealización (70 casos) fue la estrategia preferida, seguida de la polarización ( 55 casos) y de la mitigación ( 44 casos); la omisión solo se presentó en 8 del total de los titulares estudiados (173).

\section{Presencia de partidos politicos en los titulares}

Los resultados derivados del análisis de la presencia/ausencia -implícita o explícita- de partidos políticos aparecidos en los titulares mostraron que el discurso periodístico de El País se centra más en los personajes concretos (y esencialmente en los "villanos", como se ha expuesto) y solo de manera muy residual en los partidos políticos. De los 14 partidos políticos con presencia en el arco parlamentario español (véase Figura 6) para el año de la muestra, 2016, solamente los dos principales encuentran una referencia explícita dentro del corpus del análisis. Eso sí, cabe destacar que la presencia de uno (PP) y otro (PSOE) es divergente (véase Figura 7).

La distribución de partidos entre cabeceras también es diversa: mientras que El Pais hace mayor cantidad de referencias al PP, El Mundo se refiere más veces al PSOE como sujeto de la corrupción, aunque el PP le sigue de cerca. En concreto, El Pais hace 19 referencias temáticas al PP y solo dos al principal partido en la oposición, el PSOE. En el caso de El Mundo, se hicieron 24 referencias al PSOE y 21 al PP. Lejos de realizar un análisis sobre la presencia de una mayor cantidad de noticias relacionadas con el PP (para lo que habría que desentrañar la repetición noticiosa y no temática, la oportunidad de la fecha de recolección de datos, etc.) o el PSOE, sí es interesante reparar en la proporcionalidad de la representación de partido. Es más, a la luz de los datos, se podría afirmar que los casos de corrupción del PSOE están infrarrepresentados en El Pais.

Respecto al uso de las siglas en los titulares, ambos diarios se refieren al PP, directamente, en un número mayor de ocasiones. En El País, las siglas PP aparecen en un 23,7\% de las ocasiones; mientras que las del PSOE solo aparecen en un 5,2\% de las noticias relacionadas con los casos de corrupción en los cuales se encuentra implicado el partido. Por su parte, en El Mundo, las siglas del PSOE se muestran en un 2,4\% de las ocasiones, y las del PP en un $57,1 \%$ de los titulares referidos a casos de corrupción del mismo. 


\section{Conclusiones}

Esta investigación basada en el análisis de 331 titulares (158 aparecidos en $E l$ Pais, y 173 en ElMundo) tiene como conclusión principal la existencia de un discurso muy homogéneo sobre la corrupción entre ambos diarios.

En primer lugar, del análisis sobre los personajes se puede concluir que en las cabeceras de los dos periódicos el discurso mediático acerca de la corrupción política se centra en personajes concretos, que son, sobre todo, corruptos y además villanos. Los titulares sobre la corrupción están focalizados en denunciar a los corruptos (los diferentes protagonistas de los casos de corrupción) y obvian a los corruptores (el sistema político o los partidos políticos), que son los responsables al fin y al cabo de los actos de corrupción. Es más, la muestra estudiada ofrece un relato donde los villanos parecen ser los únicos culpables. De este modo, tanto El País como El Mundo omiten cualquier tipo de vínculo entre corrupción y partidos políticos o grupos financieros en sentido amplio.

Solo en cuatro ocasiones - de las 173 analizadas- El Mundo titula haciendo referencia a una empresa o a una cúpula de poder como protagonista y responsable del caso de corrupción. Además, la solución que al parecer proponen ambos medios, según la disputa entre los personajes, es que los villanos sean detenidos o juzgados. Así visto parece que el conflicto no es sistémico sino coyuntural. El relato se reduce al recuento de individuos aislados o grupos de corruptos, que operan sin conexión con el sistema, las normativas o las leyes. El delito, por tanto, se muestra descontextualizado y solo se centra en los culpables -villanos- y en el buen hacer de los agentes de la ley -en su mayoría héroes-.

En segundo lugar, a la luz de los resultados obtenidos, se puede concluir que las estrategias discursivas más aparecidas en los titulares fueron la polarización, en el caso de El País, y la idealización, en el caso de El Mundo. Ambas estrategias no desarrollan o muestran datos ni realizan análisis de las verdaderas causas de la corrupción. Centrada la polarización en la confrontación y el conflicto entre buenos y malos, y la idealización en el buen hacer de los agentes del orden y del Gobierno, la corrupción sigue sin tener explicación para los lectores. No existen conexiones entre las relaciones que se dan entre los personajes, el contexto o el sistema, y se generan informaciones muy pobres y simplificadas. El lector podrá cuestionar a determinados actores políticos, que verá como “culpables”, pero difícilmente irá más allá o reflexionará sobre las relaciones de estos con estructuras subyacentes como las leyes, el gobierno o las empresas. 
En tercer lugar, el análisis de la presencia/ausencia -implícita o explícita- de partidos políticos en los titulares de corrupción política ha mostrado diferencias significativas entre ambos diarios. Además, se puede concluir que El Mundo relaciona de una forma mucho más clara y directa corrupción y partidos políticos que El Pais. En el caso de El Mundo, hay, aproximadamente, el mismo número de titulares que tratan casos de corrupción del PP que del PSOE. No obstante, El País parece no informar de muchos de los casos relacionados con el PSOE. Esto podría significar un sesgo relacionado con su línea editorial.

Respecto al análisis de si los titulares utilizaban las siglas de los partidos al abordar las noticias sobre corrupción de los mismos, se pudo concluir que no existen diferencias significativas entre las cabeceras de los dos diarios. En ambos casos se podría decir que no se hace un uso reiterado de la partidización noticiosa; es decir, no existe una utilización generalizada de los partidos políticos en los titulares, ya sea porque se subsumen las responsabilidades-autorías dentro de los nombres otorgados a las causas y macrocausas (no es necesario destacar "PP" en un titular/noticia sobre la "trama Gürtel"), o porque se centran más en los personajes concretos y villanos que en las estructuras y personajes abstractos, continuando así con una política discreta de personificación e individualización de la corrupción frente a análisis sistémicos.

Cabe señalar cierta editorialización en los usos de los referentes partidistas, pues no se aprecia proporcionalidad en las apariciones de PP y PSOE en los titulares, destacándose una mayor presencia de titulares con referencias explícitas al PP en ambos diarios. Dado que El Mundo opta en más ocasiones por conectar corrupción y partidos, y por utilizar las siglas de forma más habitual en relación con los casos, podría significar quizás una intencionalidad de denuncia.

Los titulares analizados se han centrado únicamente en ciertos aspectos de la corrupción: los personajes, sus roles, las estrategias y la presencia/ausencia de los partidos en el contenido de las noticias - a las que hacen alusión los titulares-y los titulares. Este fenómeno muestra que aún hay importantes desafíos para desarrollar un periodismo de índole más especializada en la temática. Del mismo modo cabe destacar el sesgo de la información que está recibiendo la ciudadanía.

Obviar la relación entre un sujeto corrupto concreto y un corruptor más abstracto impide identificar o dimensionar como es debido esta lacra; al igual que sobre-representar determinados partidos políticos más alejados de la línea editorial, pues se crean espejismos de corrupción que, pese a estar 
basados en un principio de realidad, conducen a una distorsión progresiva de la realidad a partir del principio de repetición intencional.

El tratamiento particular que se desprende del análisis de los titulares se enfoca, por tanto, en las malas prácticas de unos sujetos individuales sin abordar el carácter endémico de este problema. El peligro de sostener una prensa como la actual induce a repetir los mismos errores que hasta la fecha han dado por hecho que el rol de los medios es proponer visiones o valores.

En resumen, parece que El Pais y El Mundo han tomado un camino simplificador y sesgado sobre los contextos donde se desarrollan los casos de corrupción política, sin otorgar profundidad a sus análisis. En este sentido, es importante reivindicar la necesidad de promover un enfoque más crítico en el tratamiento de la corrupción. En el actual panorama español, en el cual cada mes aparece un nuevo caso o escándalo político, es ineludible proponer una cobertura informativa con claves interpretativas de calidad que permitan a la ciudadanía desarrollar un pensamiento crítico.

\section{Referencias}

Akçay, S. (2006), "Corruption and Human Development", en Cato Journal, vol. 26, núm. 1, Estados Unidos: Cato Institute.

Aruguete, N. y Zunino, E. (2010), "El encuadre de las noticias", en Luchessi, L. [comp.], Nuevos escenarios detrás de las noticias: agendas, tecnologías y consumos, Argentina: La Crujía.

Barreiro, B. y Sánchez-Cuenca, I. (2000), "Las consecuencias electorales de la corrupción”, en Historia y politica: Ideas, procesos y movimientos sociales, núm. 4, España: Universidad Complutense de Madrid.

Boehm, F. y Graf, J. (2009), "Corrupción y anticorrupción: una perspectiva neoinstitucional”, en Revista de Economía Institucional, vol. 11, núm. 21. Disponible en: https://revistas.uexternado.edu.co/index.php/ecoins/article/view/368 [12 de marzo de 2017].

Caciagli, M. (1996), "Clientelismo, corrupción y criminalidad organizada", en Cuadernos y debates, núm. 60, España: Centro de Estudios Constitucionales.

Canel, M. J. y Sanders, K. (2005), "El poder de los medios en los escándalos políticos: La fuerza simbólica de la noticia icono", en Análisi, núm. 32, España: Universidad Autónoma de Barcelona.

Canel, M. J. y Sanders, K. (2006), Morality Tales: political scandals and journalism in Britain and Spain in the 1990s, Estados Unidos: Hampton Press. DOI: $10.1177 / 1940161208316153$.

Castells, Manuel (2003), La Era de la Información: economia, sociedad, cultura y poder, vol. II, España: Siglo XXI.

CIS [Centro de Investigaciones Sociológicas] (2016), "Barómetro de octubre 2016", núm. 3114, España: Centro de Investigaciones Sociológicas. 
Corzo, S. (2002), "El clientelismo político como intercambio", en Institut de Ciències Politiques i Socials, núm. 206, España: Universidad Autónoma de Barcelona.

Entman, R. (1993), "Framing: Toward clarification of a fractured paradigma”, en Journal of Coomunication, núm. 43, Reino Unido: Wiley On-line.

El Pais (2016), "La preocupación por la corrupción se dispara ocho puntos entre los españoles, según el CIS”, en El País, 9 marzo, España: El País.

Fairclough, N. (1989), Language and Power, Inglaterra: Longman.

Fowler, R. et al. (1979), Language and Control, Inglaterra: Routledge \& Kegan Paul.

Gallardo-Paúls, Beatriz y Enguix, Salvador (2014), "Estrategias de encuadre discursivo en periodismo político: análisis de un corpus de titulares”, en Círculo de Linguistica Aplicada a la Comunicación, núm. 58, España: Universidad Complutense de Madrid. Disponible en: http://www.ucm.es/info/circulo/no58/gallardo.pdf [3 de enero de 2017].

Goffman, E. (1974), Frame Analysis: An Essay on the Organization of Experience, Estados Unidos: Harper \& Row.

González, J. (1999), “Corrupción, democracia y responsabilidad política”, en Isonomía: Revista de Teoría y Filosofía del Derecho, núm. 10, México: Instituto Tecnológico Autónomo de México.

Hierro, J. L. (2014), Informe sobre las causas de la corrupción en la sociedad española actual: economía sumergida y comercio ilícito en España, España: Universidad Complutense de Madrid. Disponible en: http://www.thinkcom.es/pdf/informe_causas_corrupcion. pdf [ 5 de enero de 2016].

Hodgson, G. y Jiang, S. (2008), "La economía de la corrupción y la corrupción de la economía: una perspectiva institucionalista”, en Revista de Economía Institucional, núm. 10, Colombia: Universidad Externado de Colombia.

Jorques, Daniel (2000), Discurso e información. Estructura de la prensa escrita, España: Universidad de Cádiz.

Kaufmann, Daniel (2000), "Corrupción y reforma institucional: el poder de la evidencia empírica”, en Instituto del Banco Mundial, vol. 2, núm. 3, Estados Unidos: Instituto del Banco Mundial.

Labio-Bernal, A. (2006), "Del estereotipo al amarillismo: prácticas periodísticas incorrectas en el tratamiento de grupos sociales vulnerables”, en Anàlisi: Quaderns de comunicació i cultura, núm. 33, España: Universidad Autónoma de Barcelona.

Laguna, A. (2013), "La percepción de la corrupción, factor mediatizante de la democracia”, en Revista de Ciencias Sociales, núm. 8, vol. 1, España: Universidad de Alicante. DOI: 10.14198/OBETS2013.8.1.03.

Larrú, J. M. (2009), “Corrupción y ayuda al desarrollo evidencias, teoría y aplicaciones para España”, en Cuadernos Económicos de ICE, núm. 78, España: Ministerio de Industria, Comercio y Turismo.

Martínez-Gallego, F. A. (2013), "Medios de comunicación y escándalos de corrupción en España: ¿denunciantes, magnificadores, cómplices?”, en Revista de Ciencias Sociales, núm. 8, vol. 1, España: Universidad de Alicante. DOI: 10.14198/obets2013.8.1.04.

Martínez-Albertos, José Luis (1994), "La tesis del perro guardián: revisión de una teoría clásica”, en Estudios sobre Mensaje Periodístico, núm. 1, España: Universidad Complutense de Madrid. 
Martínez-Albertos, José Luis (1999), "El periodismo en el siglo XXI: más allá del rumor y por encima del caos”, en Estudios sobre Mensaje Periodístico, núm. 5, España: Universidad Complutense de Madrid.

Mauro, P. (2002), “The Persistence of Corruption and Slow Economic Growth", en IMF Working Paper, noviembre. Disponible en: https://ssrn.com/abstract=880888 [6 de diciembre de 2017].

Muñoz-López-Carmona, R. (2012), “¿Nos importa, realmente, la corrupción?”, en Dendra Médica. Revista de Humanidades, núm. 2, vol. 11, España: Mediscript.

Ordóñez, D. (2012), "La financiación de los partidos políticos en España: corrupción y deslegitimación”, en Análisis, núm. 2, vol. 2, España: Universidad Autónoma de Barcelona.

Pérez-Tapias, J. (1995), "El homo moralis y su ciudadanía democrática. A propósito de la corrupción: democracia y moral en perspectiva antropológica”, en Gazeta de Antropología, núm. 11, España: Universidad de Granada.

Pérez, Juan Francisco y López, Francisco Javier (2014), "La credibilidad del sistema democrático español: partidos políticos y corrupción”, en Revista de Derecho Público, núm 80, Chile: Universidad de Chile. DOI: 10.5354/0719-5249.2014.33322.

Quizilbash, M. (2001), “Corruption and Human Development: A Conceptual Discussion”, en Oxford Development Studies, núm. 29, vol. 3, Reino Unido: Taylor \& Francis. DOI: $10.1080 / 13600810120088868$.

Reese, S. (2001), "Framing public life: a bridging model for media research", en Reese, S. et al. [eds.], Framing public life: perspectives on media and our understanding of the social world, Estados Unidos: Lawrence Erlbaum.

Rehren, A. (2000), “Clientelismo político, corrupción y reforma del Estado en Chile”, en Documento de Trabajo, núm. 305, Chile: Centro de Estudios Públicos.

Scheufele, D. A. (1999), "Framing as a theory of media effects", en Journal of Communication, núm. 49, vol. 1, Reino Unido: Wiley On-line.

Sola-Morales, S. y Rivera, R. (2017), "El tratamiento periodístico sobre la corrupción política. Análisis comparado del caso SQM en Chile y del caso de Bárcenas en España”, en Estudios sobre el Mensaje Periodístico, vol. 23, núm. 1, España: Universidad Complutense de Madrid. DOI: 10.5209/ESMP.55619.

Sola-Morales, S. (2014), "La construcción narrativa de la realidad cotidiana. Una revisión desde los media frames”, en Doxa Comunicación. Revista Interdisciplinaria de Estudios de Comunicación y Ciencias Sociales, núm. 18, España: Universidad Complutense de Madrid.

Sola-Morales, S. (2012), “¿Víctimas o heroínas? Un análisis crítico de los blogs ‘Mujeres’ y 'En Femenino”, en Discurso \& Sociedad, vol. 6, núm. 4. Disponible en: http://www. dissoc.org/ediciones/v06n04/DS6\%284\%29Sola.pdf [1 de abril de 2017].

Tankard, J. (2001), "The empirical approach to the study of media framing”, en Reese, S. et al. [eds.], Framing public life: perspectives on media and our understanding of the social world, Estados Unidos: Lawrence Erlbaum.

Transparencia Internacional (2016), “Corruption Perception Index 2016”. Disponible en: https://www.transparency.org/news/feature/corruption_perceptions_index_2016\#table [14 de febrero de 2018].

Van Dijk, T. A. (1980), Macrostructures. An Interdisciplinary Study of Global Structures in Discourse, Interaction and Cognition, Estados Unidos: Erlbaum. 
Van Dijk, T. A. (1990), La noticia como discurso: comprensión, estructura y producción de la información, España: Paidós.

Van Dijk, T. A. (1991), Estructuras y funciones del discurso: una introducción interdisciplinaria a la lingüistica del texto y a los estudios del discurso, México: Siglo XXI.

Zamora, R. y Marín, J. (2010), "La representación simbólica del escándalo de corrupción política. Hacia una tipología de los marcos periodísticos (frames) utilizados en la narración del escándalo de corrupción política”, en Razón y Palabra, núm. 73, vol. 15, México: Tecnológico de Monterrey.

Zamora, R. y Marín, J. (2011), “Un modelo para analizar la representación simbólica del escándalo de corrupción política desde la teoría del framing: aplicación al 'caso Umbra”, en Miguel Hernández Communication Journal, núm. 2, España: Universitas. 


\section{Anexo}

\section{Figura 1}

\section{La corrupción, segundo problema de España}

Barómetro del CIS, febrero de 2016

\section{¿Cuál es el principal problema que existe actualmente en España? \\ Multirrespuesta}

\section{LA CORRUPCIÓN Y EL FRAUDE}

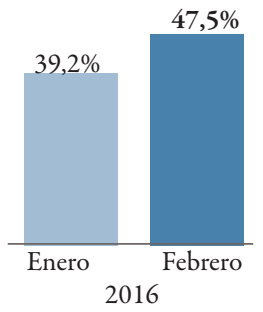

\begin{tabular}{lcc} 
& \multicolumn{2}{c}{2016} \\
En \% & Enero & Febrero \\
\hline El paro & 77,9 & 78,0 十 \\
\hline La corrupción y el fraude & 39,2 & 47,5 \\
\hline Los problemas económicos & 23,2 & $25,1 \star$ \\
\hline Los políticos y los partidos & 23,4 & $22,2 \downarrow$ \\
\hline Los problemas sociales & 11,7 & $11,4 \downarrow$ \\
\hline
\end{tabular}

\section{¿Cómo calificaría}

la situación política de España?

En \%

Enero

Febrero

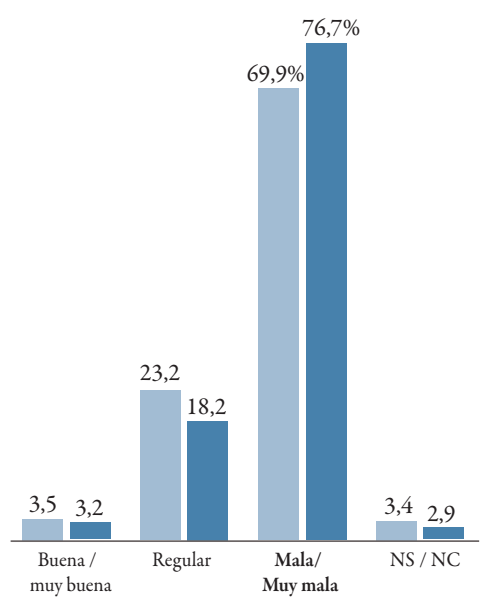

FICHA TÉCNICA. 2478 entrevistas a españoles de ambos sexos de 18 y más años en 256 municipios y 46 provincias. Cuestionarios mediante entrevista personal en los domicilios. Error muestral: para un nivel de confianza del $95.5 \%$ (dos sigmas), y $\mathrm{P}=\mathrm{Q}$, el error real es de $\pm 2,0 \%$ para el conjunto de la muestra. Fecha de realización: del 1 al 11 de febrero de 2016.

Fuente: Gráfica publicada en El País, en CIS (2016). 
Figura 2

\section{Tipos de personajes}

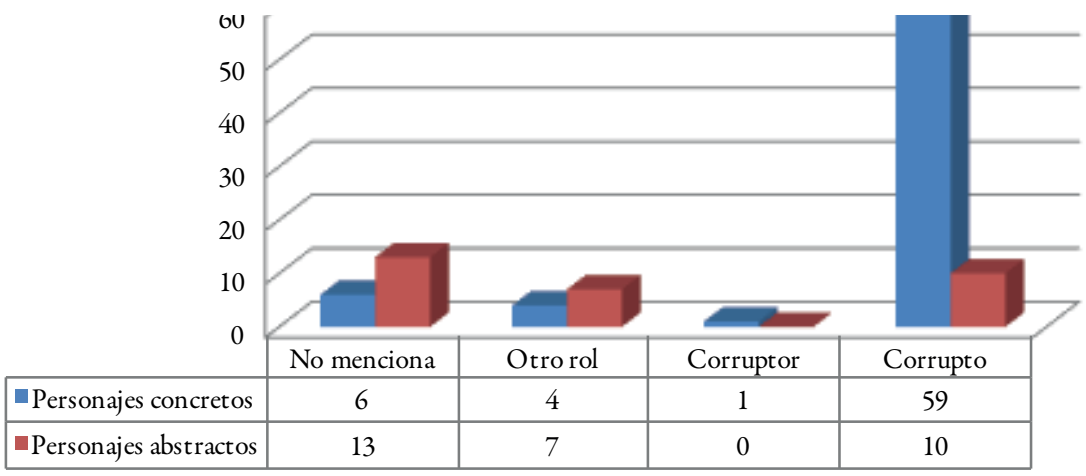

Fuente: Elaboración propia.

Figura 3

\section{Rol de los personajes concretos}

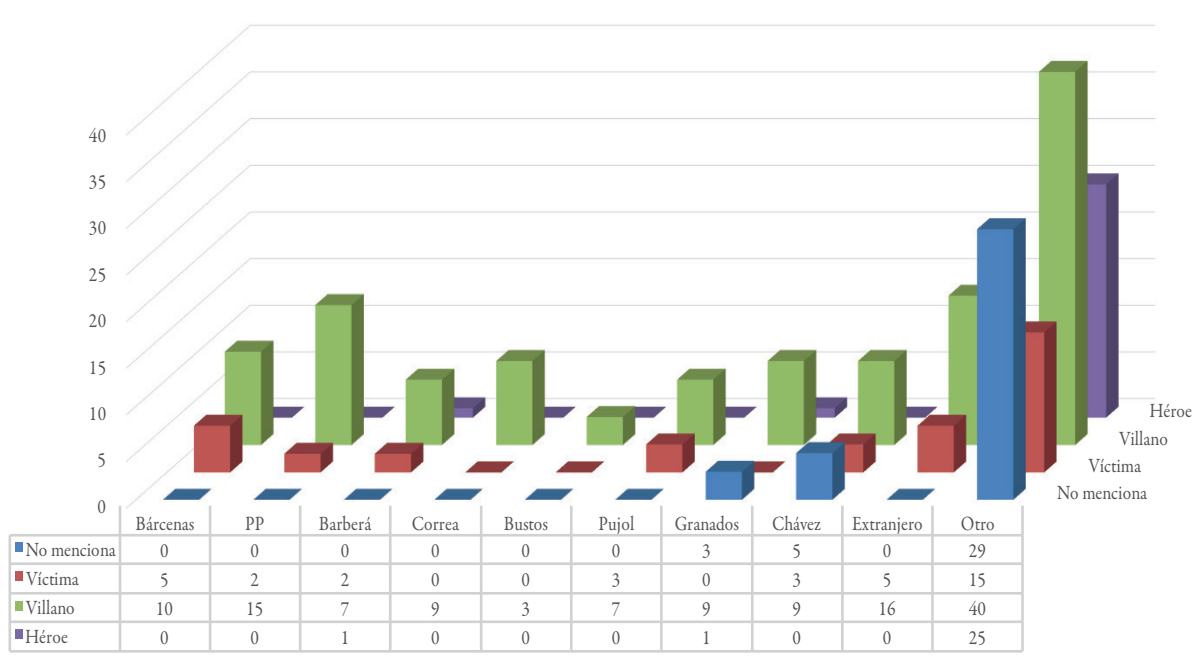

Fuente: Elaboración propia. 
Figura 4

\section{Rol de los personajes abstractos}

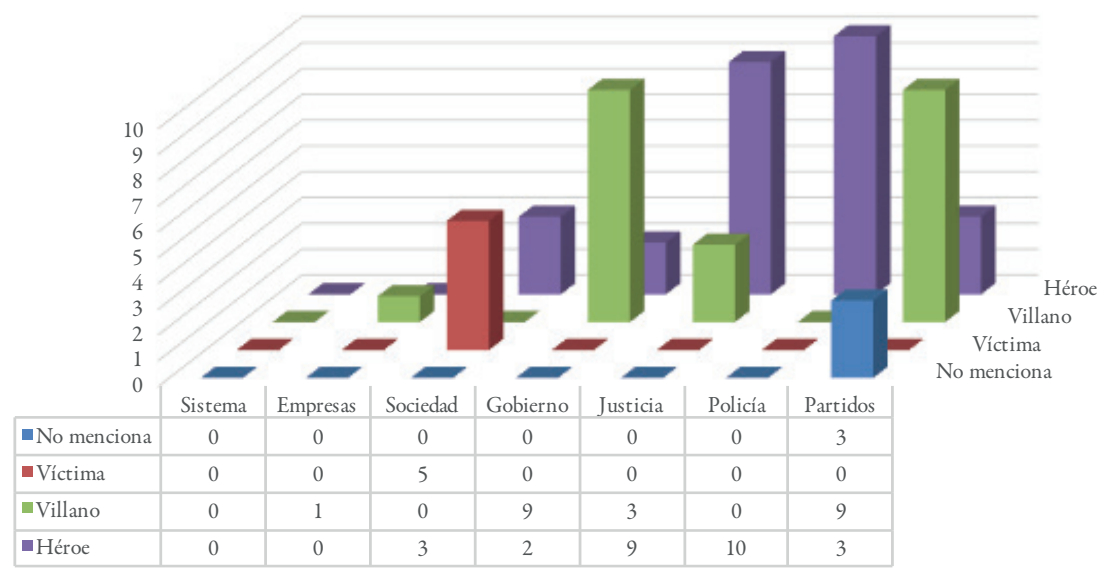

Fuente: Elaboración propia.

Figura 5

Estrategias discursivas

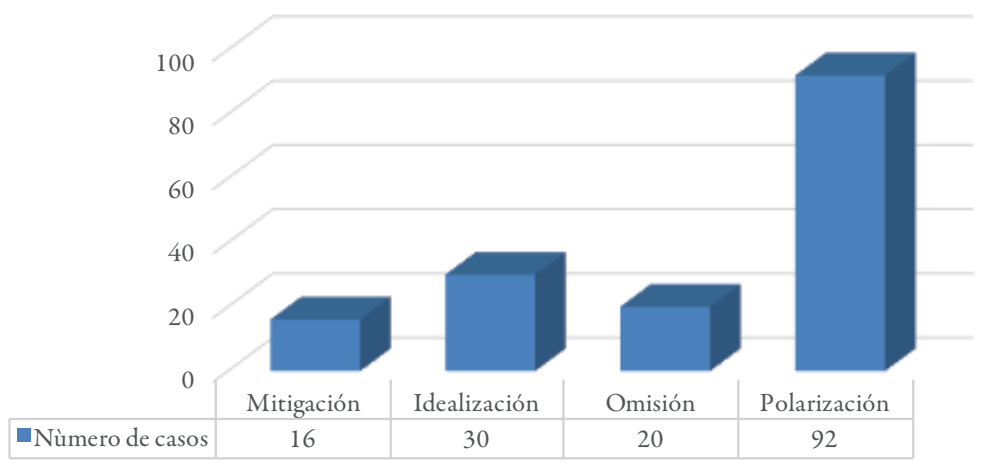

Fuente: Elaboración propia. 
Figura 6

\section{Gobierno español 2016}

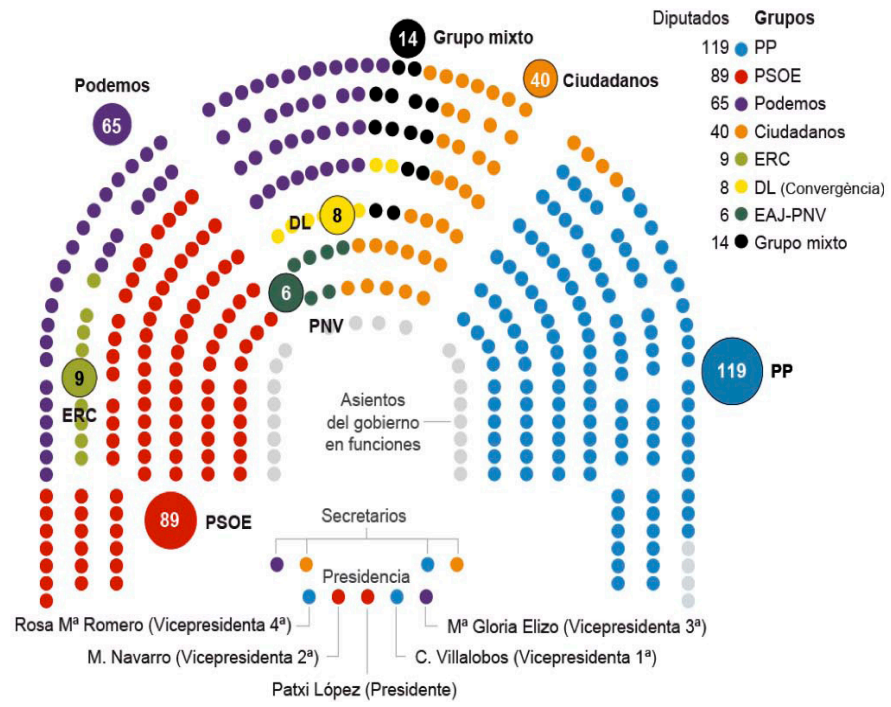

Fuente: El Pais (2016).

\section{Figura 7}

Presencia de partidos políticos en los titulares

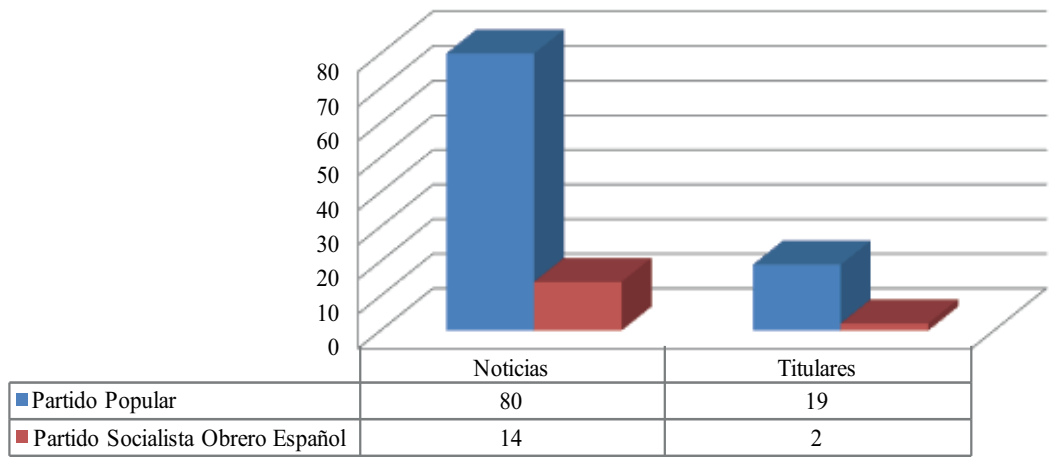

Fuente: Elaboración propia. 


\section{Tabla 1}

\section{Rol de los personajes concretos de El País}

\begin{tabular}{|c|c|c|c|c|c|c|c|c|c|c|c|}
\hline & 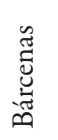 & $\hat{a}$ & 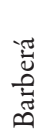 & 节 & $\begin{array}{c}\tilde{0} \\
\stackrel{0}{0} \\
\tilde{0}\end{array}$ & $\vec{\Xi}$ & 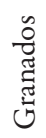 & 总 & 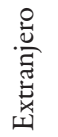 & $\stackrel{\mathscr{B}}{0}$ & 䀡 \\
\hline No menciona & 0 & 0 & 0 & 0 & 0 & 0 & 3 & 5 & 0 & 29 & 37 \\
\hline Víctima & 5 & 2 & 2 & 0 & 0 & 3 & 0 & 3 & 5 & 15 & 35 \\
\hline Villano & 10 & 15 & 7 & 9 & 3 & 7 & 9 & 9 & 16 & 40 & 125 \\
\hline \multirow[t]{2}{*}{ Héroe } & 0 & 0 & 1 & 0 & 0 & 0 & 1 & 0 & 0 & 25 & 25 \\
\hline & & & & & & & & & & & 222 \\
\hline
\end{tabular}

Fuente: Elaboración propia.

Tabla 2

Rol de los personajes concretos de $E l$ Mundo

\begin{tabular}{|c|c|c|c|c|c|c|c|c|c|c|c|}
\hline & 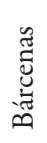 & $\hat{\beth}$ & صृّ & 节 & $\begin{array}{l}\stackrel{0}{0} \\
\stackrel{0}{0} \\
\ddot{n}\end{array}$ & $\stackrel{\overrightarrow{0}}{\stackrel{\Xi}{a}}$ & 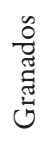 & 悹 & 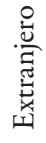 & $\stackrel{\circ}{0}$ & 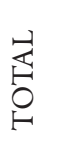 \\
\hline No menciona & 0 & 0 & 0 & 0 & 0 & 0 & 3 & 0 & 5 & 7 & 15 \\
\hline Víctima & 0 & 3 & 2 & 0 & 0 & 0 & 0 & 1 & 0 & 15 & 21 \\
\hline Villano & 1 & 1 & 0 & 0 & 1 & 3 & 9 & 1 & 3 & 48 & 66 \\
\hline Héroe & 0 & 5 & 0 & 0 & 0 & 0 & 1 & 0 & 0 & 44 & 50 \\
\hline
\end{tabular}

Fuente: Elaboración propia. 


\section{Tabla 3}

\section{Rol de los personajes abstractos de El País}

\begin{tabular}{|c|c|c|c|c|c|c|c|c|}
\hline & 芯 & 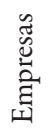 & 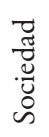 & $\begin{array}{l}0 \\
\stackrel{0}{0} \\
\stackrel{0}{0} \\
0 \\
0\end{array}$ & & \begin{tabular}{l}
$\frac{\pi}{\mathscr{n}}$ \\
$\frac{0}{0}$ \\
\hdashline
\end{tabular} & $\frac{\mathscr{0}}{0}$ & ت્ّ \\
\hline No menciona & 0 & 0 & 0 & 0 & 0 & 0 & 3 & 3 \\
\hline Víctima & 0 & 0 & 5 & 0 & 0 & 0 & 0 & 5 \\
\hline Villano & 0 & 1 & 0 & 9 & 3 & 0 & 9 & 22 \\
\hline Héroe & 0 & 0 & 3 & 2 & 9 & 10 & 3 & 27 \\
\hline
\end{tabular}

Fuente: Elaboración propia.

Tabla 4

Rol de los personajes abstractos de El Mundo

\begin{tabular}{|c|c|c|c|c|c|c|c|c|}
\hline & 节 & 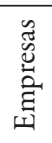 & 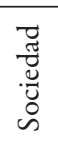 & $\begin{array}{l}0 \\
\stackrel{0}{0} \\
0 \\
0 \\
0 \\
0\end{array}$ & 䔍 & 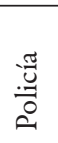 & $\frac{0}{0}$ & $\stackrel{\vec{\Xi}}{\stackrel{0}{0}}$ \\
\hline No menciona & 2 & 0 & 2 & 2 & 1 & 0 & 0 & 7 \\
\hline Víctima & 0 & 0 & 0 & 2 & 0 & 0 & 0 & 2 \\
\hline Villano & 1 & 3 & 0 & 2 & 0 & 0 & 0 & 6 \\
\hline Héroe & 1 & 1 & 2 & 2 & 2 & 0 & 0 & 8 \\
\hline
\end{tabular}

Fuente: Elaboración propia. 
Salomé Sola-Morales. Doctora en Medios, Comunicación y Cultura. Investigadora del Grupo Interdisciplinario de Estudios en Comunicación, Política y Cambio Social (Compoliticas) y Asistente Honorario del departamento de Periodismo 1, de la Universidad de Sevilla. Líneas de investigación: teorías de la comunicación, narrativa audiovisual, entornos virtuales, procesos identitarios y política. Publicaciones recientes: Sola-Morales, S. (2018), "Cuerpos y comunidades de pertenencia en Internet: Análisis de blogs Pro-Ana y Pro-Mía”, en Reyes-García, P. [ed.], Vinculos, divergencias y relaciones. Ensayos sobre ciencia, tecnología y sociedad, Chile: RIL Editores; Sola-Morales, S. y Hernández-Santaolalla, V. (2017), "Voter Turnout and New Forms of Political Participation of Young People: A Comparative Analysis between Chile and Spain”, en Revista Latina de Comunicación Social, núm. 72. Disponible en: http://www.revistalatinacs.org/072paper/1183/33en.html. DOI: 10.4185/RLCS-2017-1183; Sola-Morales, S. (2017), "The villainous man: Evil as the embodiment of masculinity", en Rey, J. [ed.], All about Almodóvar's Men, Estados Unidos: Peter Lang.

Belén Zurbano-Berenguer. Doctora en Periodismo por la Universidad de Sevilla. Profesora del Centro Campus Universitario de la Cámara de Comercio (EUSA), Centro Adscrito a la Universidad de Sevilla. Líneas de investigación: teorías de la comunicación, estudios de género e investigación teórico-práctica sobre la calidad periodística. Publicaciones recientes: Martínez-Jiménez, L. y Zurbano-Berenguer, B. (2018), "Perdóname señor. Construcción identitaria y estrategias de supervivencia de la(s) feminidad(es) andaluza(s) en la ficción popular”, en Dígitos (en prensa), España: Universidad de Valencia; Zurbano-Berenguer, B. (2018), "Comunicación, periodismo y violencias contra las mujeres en España. Reflexiones en torno a un estado de la cuestión”, en Revista Observatorio, vol. 4, núm. 2, Portugal: Instituto Universitario de Lisboa; Barredo-López, D. et al. (2017), "La violencia de género en Ecuador: un estudio sobre los universitarios”, en Estudos Feministas, vol. 25, núm. 3, Brasil: Universidade Federal de Santa Caterina. 